\title{
Remaining Life Assessment of Superheater Tube in Boiler of Coal Fired Power Plant
}

\author{
Habib Muhajir ${ }^{1, *}$, Gunawan Dwi Haryadi ${ }^{1}$, and Achmad Widodo ${ }^{1}$ \\ ${ }^{1}$ Departement of Mechanical Engineering Faculty of Engineering, UNDIP, 50275 Semarang, \\ Indonesia
}

\begin{abstract}
Risk Based Inspection (RBI) would be able to establish an effective structural integrity management program, which reduces plant downtime, industry and regulatory burdens, and continue to maintain plant safety. The object of this research is final superheater of boiler coal fired power plant. Both straight tube and elbow tube of final superheater is in a medium risk category. Elbow tube has higher risk ranking because of the higher corrosion rate due to fly ash corrosion. The remaining life of straight tube is about 26 years and elbow tube is only about 7 years using corrosion rate calculations. Base on risk ranking and remaining life assessment, inspection planning can be developed for the next 3 years and prioritize at an elbow tube of the final superheater section. It can be one of the considerations for the company to pending yearly inspection in order to improve cost efficiency and reduce downtime.
\end{abstract}

\section{Introduction}

Boiler tube failures are one of the important reasons for unexpected shut down of power plants. The cost penalty is estimated to be in excess of $\$ 5$ billion a year in replacing power charges and maintenance [1].

Last decade shown a trend where the life management program is globally moving from prescribed/time based towards risk based decision making. RBI would be able to establish an effective structural integrity management program, which reduces plant downtime, industry and regulatory burdens, and continue to maintain plant safety [2].

In Europe and the United States, major oil companies have already implemented RBI technique several years ago. In Japan, the RBI has lately attracted considerable attention as a new technique for maintenance planning of fossils fired power and petrochemical plants that will be deregulated [3].

This research uses data thickness, final superheater section as representative data all of the boiler because of criticality that operate in highest pressure and temperature. It consist of 84 panels which each panel is given in Figure 1 [4]. Data thickness of the tube is taken in front of the flue gas side that the most suffering fly ash erosion at straight tube and elbow tube.

\footnotetext{
*Corresponding author: habib pjbs@yahoo.co.id
} 


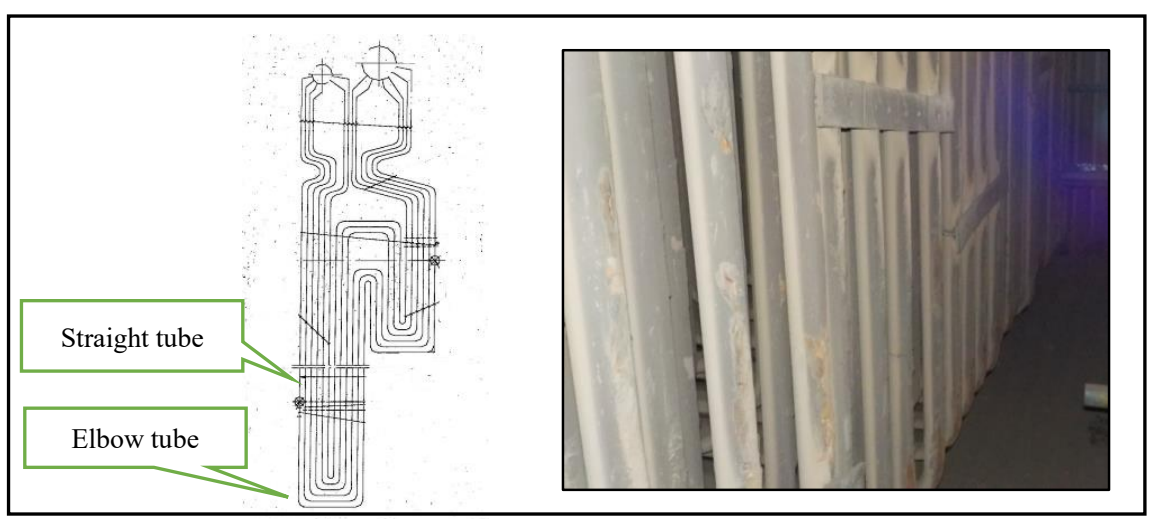

Figure 1. Drawing \& picture panel of final superheater [5]

The information about boiler final superheater is shown in Table 1.

Table 1. Operation data of final superheater tube

\begin{tabular}{|c|c|c|c|c|}
\hline $\begin{array}{c}1{ }^{\text {st }} \text { Year } \\
\text { Operation }\end{array}$ & $\begin{array}{c}\text { Tube } \\
\text { Dimension } \\
\end{array}$ & Material & $\begin{array}{c}\text { Steam } \\
\text { Pressure }\end{array}$ & $\begin{array}{c}\text { Steam } \\
\text { Temperature }\end{array}$ \\
\hline April 2011 & $\theta 51 \times 8 \mathrm{~mm}$ & SA-213T91 & $17.26 \mathrm{Mpa}$ & $541^{\circ} \mathrm{C}$ \\
\hline
\end{tabular}

\section{Methodology}

\subsection{Risk Based Inspection}

The calculation of risk in the RBI methodology involves the determination of a probability of failure combined with the consequence of failure [5]. With the use of the RBI method, high-risk tools get special handling and equipment with lower risk levels can be handled as necessary so as to reduce excessive inspection [6].

There are three types of RBI method that are qualitative, semi quantitative, and quantitative. Qualitative methods are methods that analyze using the general categorization. While the quantitative method is a method that analyzes based on the calculation of complex data. The semi-quantitative method is a mid-method between qualitative and quantitative, in that the result is more accurate than qualitative but the count is not as complex as quantitative. Calculating both elements using Appendix B-Workbook for Semi-Quantitative Risk-Based Inspection Analysis on API 581 Publication. The possibility of failure of the RBI API is calculated using the equation:

$$
\mathrm{PF}=\mathrm{GFF} \times \mathrm{FMS} \times \mathrm{DF}
$$

In the equation, the possibility of failure (PF), general frequency failure (GFF), damage factors (DF), and factor management systems (FMS). There are several steps to get the consequence value are determined the representative fluid and its properties, determine the leak hole, determine the total leakage, determine the rate of leakage, determine the type of leakage, determine the effects of post-leakage. The main result of an RBI method is the risk matrix that places the equipment at a certain level of risk as shown in Figure 2 [7]. 


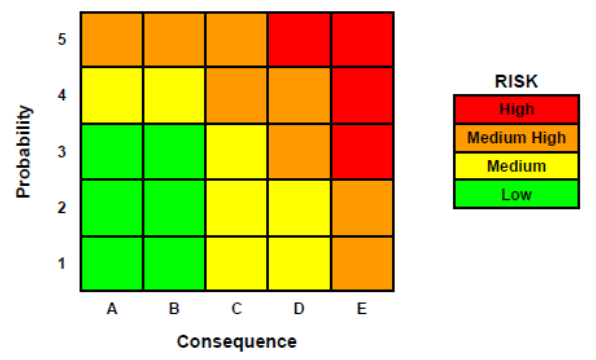

Figure 2. Risk Matrix

\subsection{Remaining Life}

Determination of equipment remaining life relates to inspection priorities. The method of determining the age of the equipment in the present study was determined by means of metal thinning analysis by $\mathrm{T}$ min determination in which the value was the minimum thickness allowed by an operational condition. Data is taken with ultrasonic thickness gauge of GE Type DMS 2 product with a precision of $0.01 \mathrm{~mm}$. According to API BRD 581 the determination of the remaining life of the equipment is calculated according to the equation formula [8]:

$$
\text { remaining life }\left(\mathrm{R}_{\mathrm{L}}\right)=\frac{\text { damage tolerance }}{\text { damage rate }}=\frac{\text { Tact }- \text { Tmin }}{\text { corrosion rate }}
$$

\subsection{Inspection Planning}

From the risk level can be made scheduling for the equipment being analyzed. Scheduling inspection look at the level of risk and also the mechanism of damage that occurs in the equipment The schedule of inspection of a device according to its risk is indicated by the following equation:

$$
\mathrm{NID}=\text { Ief } \times \mathrm{C} \times \mathrm{R}_{\mathrm{L}}
$$

In the equation of the next inspection schedule, NID, Determined as the product of the effectiveness of the inspection, Confidence rating $C$, and residual life $\mathrm{CR}_{\mathrm{L}}$. The value of the inspection effectiveness is $0-1$, the value is based on the category of effectiveness of the inspection. While the value of the confidence rating is taken based on the risk level is less than 0.5 for high risk level and more than 0.5 for low risk level. So as to reduce the method of excessive inspection and the results obtained more optimal [9].

\section{Result and discussion}

\subsection{Analisis Risk Based Inspection (RBI) Semi-Kuantitatif}

The RBI analysis based on semi-quantitative method can be calculated based on Appendix B-Workbook for Semi-Quantitative Risk Based Inspection Analysis API RBI 581.

\section{Part A: Leak Rate Calculation}

The representative fluid in this analysis is classified as Steam, the group has the characteristics as mentioned in table 7.2 API RBI 581. 
According to Table B-1 on API BRD 2000, the inventory category identification for superheater with the mentioned capacity is a category $C$ with range between $10,000-100,000$ lbs. Table 7.6 on API BRD 2000 provides guidance to the user for assigning a qualitative letter rating $(\mathrm{A}, \mathrm{B}$, or $\mathrm{C})$ to the unit's detection and isolation systems. The detection and isolation classification system defined as C and B. This is because the boiler is completed with leak detector with marginal coverage and also isolation and shutdown system is operated by an operator in the control room. Therefore, for the evaluated final superheater tube, the leak duration, liquid discharge rate, type and representative fluid phase after release are shown in Table 2 .

Table 2. Leak Duration, Liquid Discharge Rate and Type

\begin{tabular}{ccccc}
\hline Hole Size Diameter & $\begin{array}{c}\text { Leak } \\
\text { Duration }\end{array}$ & Lb/Sec & Lb/3Sec & Release Type \\
& 60 Minutes & 0.31 & 56.67 & Continuous \\
\hline 0.25 Inch & 40 Minutes & 5.03 & 906.74 & Continuous \\
1 Inch & 20 Minutes & 80.59 & $14,507.92$ & Instantaneous \\
4 Inch & Rupture & 725.39 & $130,571.24$ & Instantaneous \\
12 Inch &
\end{tabular}

\section{Part B: Likehood Analysis}

The effectiveness of the inspection of tools is classified in a fairly effective manner because the thickness measurement has been done with spot ultrasonic test (UT) method and visual inspection. The boiler has been conducted twice in inspection, in 2015 and 2016.

Damage factor thinning calculation including minimum wall thickness allowance and corrosion rate is summarized on the Table 3.

Table 3. Thickness and corrosion rate on each part

\begin{tabular}{ccccccc}
\hline Section & $\begin{array}{c}\text { Actual } \\
\text { Thickness } \\
\mathbf{2 0 1 6}\end{array}$ & $\begin{array}{c}\text { Tmin } \\
(\mathbf{m m})\end{array}$ & $\begin{array}{c}\text { Diameter } \\
\mathbf{( m m )}\end{array}$ & $\begin{array}{c}\text { Corrosion } \\
\text { Rate } \\
(\mathbf{m m} / \mathbf{y e a r})\end{array}$ & Art & $\begin{array}{c}\text { Likehood } \\
\text { Category }\end{array}$ \\
\hline Straight tube & 7.75 & 6.80 & 51.00 & 0.04 & 0.02 & 1 \\
Elbow tube & 7.47 & 6.80 & 51.00 & 0.09 & 0.06 & 2 \\
\hline
\end{tabular}

So from the value of the reduction constant and the effectiveness of the inspection obtained the value of TMSF. Adjust obtained by multiplying the TMSF value by the factor value over design and it is found that the over design factor 1 for straight tube and 2 for elbow tube.

\section{Part C: Flammable Consequence Calculation}

In this analysis, there is no HF or H2S compound in the analyzed equipment so that the $\mathrm{C} 2$ worksheet is negligible and has a value 0 . Specifies the general failure frequency value (GFF) based on the type of equipment being analyzed. In this research, the equipment type is pipe with diameter 2 inches.

Table 4. Courses flammable consequence and area

\begin{tabular}{lcccc}
\hline Hole Size & $\begin{array}{c}\text { Fraction } \\
\text { Contribution }\end{array}$ & Unit & $\begin{array}{c}\text { Flammable } \\
\text { Consequence }\end{array}$ & Flammable Area \\
\hline Small (1/4) & 0.09 & $\mathrm{ft}^{2}$ & 0.15 & 0.13 \\
Medium (1) & 0 & $\mathrm{ft}^{2}$ & 2.57 & 0 \\
Large (4) & 0 & $\mathrm{ft}^{2}$ & 887.04 & 0 \\
Rupture (12) & 0.08 & $\mathrm{ft}^{2}$ & $3,606.87$ & 306.47 \\
\hline
\end{tabular}


The extent of damage to each hole is added, then get a value of 306,598 $\mathrm{ft}^{2}$. Based on table B-2 API 581 then the equipment enters the category of the consequences of failure $\mathrm{C}$ that is between 100-1,000 $\mathrm{ft}^{2}$.

The level of risk on a semi-quantitative method API 581 are a combination of categories the possibility of failure and the consequences of failure categories. The final risk ranking is summarized in 5 x 5 matrix that shows Likelihood v's Consequence, in which the values are presented as categories.

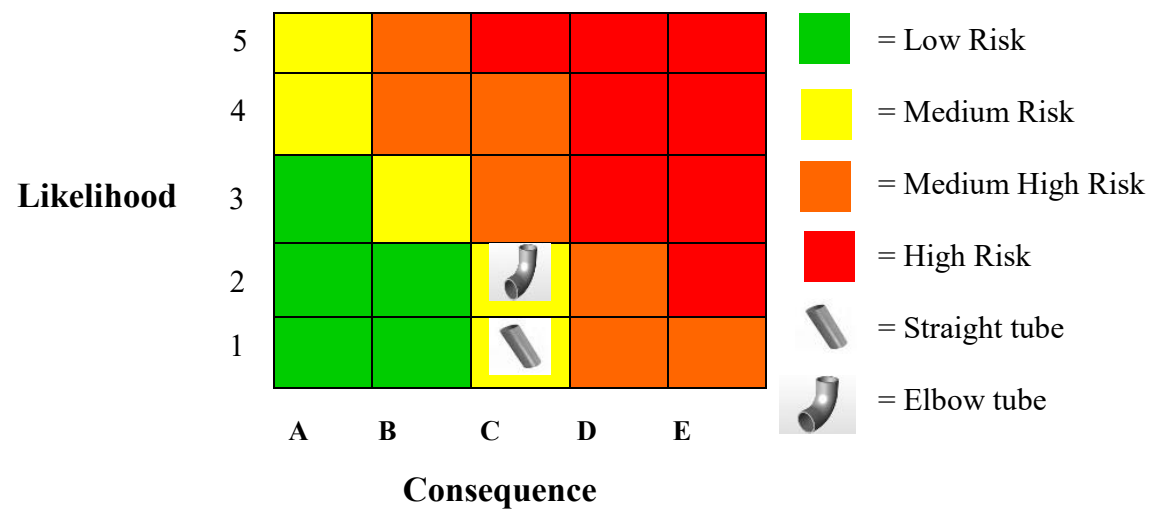

Figure 3. Risk ranking distribution

\subsection{Remaining Life}

Based on the formula of remaining life calculation using corrosion rate, the following remaining life calculation is shown in Table 5 and Figure 4.

Table 5. Remaining Life Calculation

\begin{tabular}{ccccc}
\hline Section & $\begin{array}{c}\text { T act } \\
(\mathbf{m m})\end{array}$ & $\begin{array}{c}\text { T min } \\
(\mathbf{m m})\end{array}$ & $\begin{array}{c}\text { Corrosion } \\
\text { Rate }(\mathbf{C R}) \\
(\mathbf{m m} / \mathbf{y e a r s})\end{array}$ & $\begin{array}{c}\text { Remaining Life } \\
\left(\mathbf{R}_{\mathbf{L}}\right) \\
(\text { Years })\end{array}$ \\
\hline Straight tube & 7.75 & 6.80 & 0.04 & 26.64 \\
Elbow tube & 7.47 & 6.80 & 0.09 & 7.31 \\
\hline
\end{tabular}

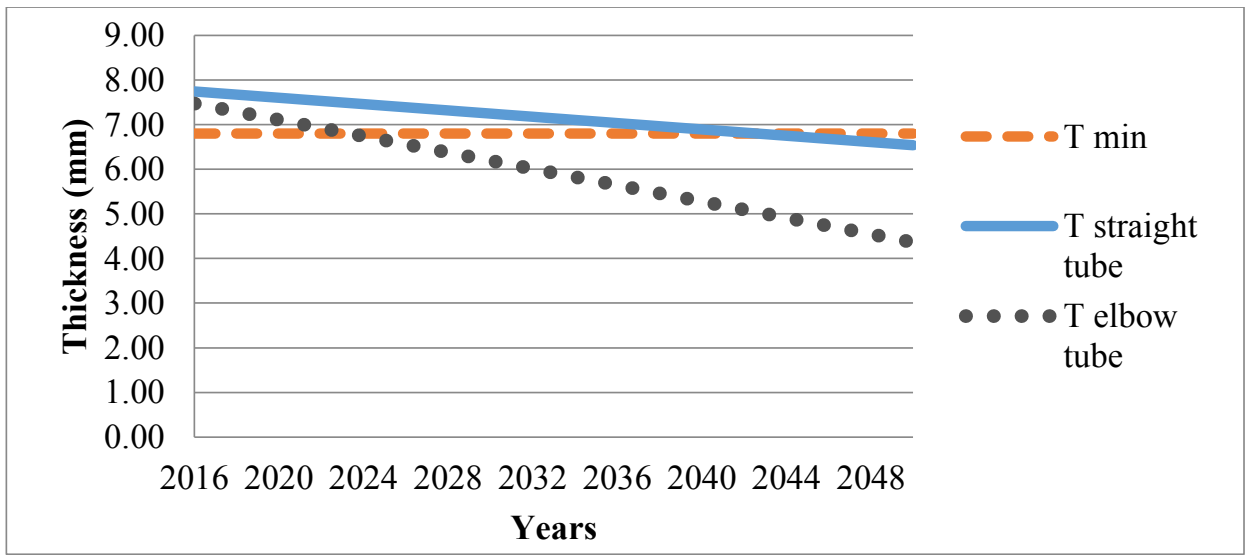

Figure 4. Remaining life tube straight tube and elbow tube 


\subsection{Inspection Planning}

Selected corrosion rates as a reference due to the most influential in residual life use. From the available data, the highest corrosion rate is $0.09 \mathrm{~mm} /$ year, then the schedule for the next inspection is as follows:

$$
\begin{gathered}
\text { NID }=I_{\text {ef }} C R_{L} \\
\mathrm{NID}=0.6 \times 0.75 \times 7.31 \text { years } \\
\mathrm{NID}=3.28 \text { years }
\end{gathered}
$$

Inspection should be done at least 3 years from the last inspection 2016. In this analysis, the equipment is damaged in the form of thinning wall thickness due to localized corrosion. Some methods that can be used are visual examination, ultrasonic tube thickness, eddy current, EMAT (Electromagnetic Acoustic Transducer), magnetic particle testing. These methods are the most effective method used for this type of thinning damage [10].

\section{Conclusions}

Both straight tube and elbow tube of final superheater is in a medium risk category. Elbow tube has higher risk ranking than a straight tube because of the higher corrosion rate due to fly ash corrosion. The remaining life of straight tube is about 26 years and elbow tube is only about 7 years using corrosion rate calculations. Base on risk ranking and remaining life assessment, inspection planning can be developed for the next 3 years and prioritize at an elbow tube of the final superheater section. It can be one of the consideration for the company to pending yearly inspection in order to improve cost efficiency and reduce downtime.

\section{References}

[1] French DN, Metallurgical failures in fossil fired boilers, 22 (New York, Wiley/Wiley-Interscience (1983).

[2] Galang Sandy Prayogo, Gunawan Dwi Haryadi1, Rifky Ismail, Seon Jin Kim et al, Risk analysis of heat recovery steam generator with semi quantitative risk based inspection API 581 (2016)

[3] Akio Fuji, Aplication of Risk Based Maintenance with life and Financial Assesment on Fossil Fired Power Plant, Oral Conference, Research Laboratory, IshikawajimaHarima Heavy Industries Co., Ltd (2000)

[4] Dongfang, Operation \& Maintenance of Boiler Manual Book for Rembang 2x300 MW Coal FIred Power Plant (2008)

[5] API RP 581 Risk-Based Inspection Technology (2008)

[6] Assesment Boiler Report 2016, PT PLN (Persero) Research Institute (2016)

[7] Moamar Al Qathafi, Sulistijono, The Application of Semi-Quantitative Risk Based Inspection Method (RBI) API 581 in Production Separator, Technical Journal ITS Vol. 4, No. 1, (2015)

[8] API Publication 581 Risk-based inspection base resource document, American Petroleum Institute (2000)

[9] Ming-Kuen Chang, et al, Application of Risk Based Inspection in Refinery and Processing Piping (2005)

[10] EPRI, Technical Report Boiler Condition Assessment Guideline (2006) 